\title{
DEMOGRAPHIC VARIABLES ASSOCIATED WITH DRUG USE IN BIPOLAR PATIENTS
}

\author{
MARIAM HAROON ${ }^{1}$, SUMIRA QAMBAR BOKHARI ${ }^{2}$, AYSHA RASHID $^{3}$, AYSHA BUTT $^{2}$, \\ NAUMAN MAZHAR ${ }^{2}$, ALI ANJUM ${ }^{2}$, SADAF SALEEM ${ }^{4}$ \\ ${ }^{1}$ Fountain House, Lahore, ${ }^{2}$ Department of Psychiatry \& Behavioural sciences, Services Institute of Medical Sciences, \\ Lahore, ${ }^{3}$ Department of Psychiatry \& Behavioural sciences, Fatimah Jinnah Medical University/Sir Ganga Ram \\ Hospital, Lahore, ${ }^{4}$ Department of Psychiatry, Punjab Institute of Mental Health, Lahore
}

\begin{abstract}
Background: Substance Use is highly associated with bipolar affective disorder, however the reason for the cooccurrence is unknown. It was evident that if a bipolar patient use drug of abuse his outcome will be poor. Either it can directly trigger the affective symptoms, or may affect the treatment compliance indirectly.

Objective: To study the demographic correlates of drug abuse in patients with bi-polar affective disorder.

Methods: Cross-Sectional research design and non-probability consecutive sampling was used to collect data from a private clinic in Lahore. Data was comprised of 368 patients of bipolar disorder.

Results: Out of a total of 368 bipolar patients, drug abuse was found in 147 patients that is $39.9 \%$. The results showed that the mean age of the patients was $31.03 \pm 5.837$; mean monthly income was $229597.82 \pm 164626.77$ PKR. The mean duration of illness was $6.54 \pm 5.157$. The mean number of drugs used was $2 \pm 0.875$. The mean cost of drug was $29945.7 \pm 19068.8$ PKR. The mean number of hospitalization was $2.47 \pm 1.694$. Association between drug use and occupation of bipolar patients (0.006), factors leading to initiation of drug use (0.000), family history of drug use (0.001), current episode (0.000) and the type of drugs used (0.000) was statistically significant.

Conclusion: The cause and effect relationship between drug use and bipolar disorder cannot be clearly identified. However occupation of the patient, reasons of initiating drugs, drug abuse in family, current episode as well as type of drugs used have significant association with drug abuse in bipolar patients .
\end{abstract}

Keywords: Demographic, Drug abuse, Biploar

How to cite this article: Haroon M, Bokhari SQ, Rashid A, Butt A, Mazhar N, Anjum A, Saleem S. Demographic variables associated with drug use in bipolar patients. Pak Postgrad Med J 2019;30(3): 114-119

This is an Open Access article distributed under the terms of the Creative Commons Attribution License (http://creativecommons.org/licenses/by/3.0), which permits unrestricted use, distribution, and reproduction in any medium, provided the original work is properly cited.

Correspondence to: Aysha Rashid, Associate Professor, Department of Psychiatry \& Behavioural sciences, Fatimah Jinnah Medical University/Sir Ganga Ram Hospital, Lahore, Pakistan.

Email:ashi.32c@gmail.com

\section{INTRODUCTION}

Bipolar disorder is a relapsing remitting disease which is reported to be prevalent in about $1 \%$ to $1.6 \%$ of the general population ${ }^{1-3}$ If the prevalence of bipolar spectrum is considered, then it may become $8.3 \%$, which comprised of sub-syndromal forms (also causes functional impairment), like substance-induced mania and mild episodes of short duration or incomplete diagnostic criteria ${ }^{4}$.

Diagnostic and Statistical Manual of Mental Disorders-5 classified Bipolar and related disorders into Bipolar I disorder which is characterized as having at least one manic episode Bipolar II disorder in which depressive episode alternate with hypomanic episode ${ }^{5}$,

Cyclothymic disorder, where lesser intensity of depressive and elated mood episode alternate, Substance or medication-induced Bipolar and related disorder, Bipolar and related disorder due to another medical condition, Other specified bipolar and related disorder, and Unspecified bipolar and related disorder. 
From literature, it is evident that Bipolar affective disorder is quite common however we know very little about its the etiology. Current research shows genetic variation in patients with Bipolar disorder and because of this hypothesis of association of bipolar disorder with common genetic factors becomes outdated. Therefore it was believed that to understand etiology, genetic information was needed to be studied on environmental and structural factors ${ }^{6}$.

Similarly, Strakowski ${ }^{7}$ explained that substance use disorders and bipolar disorder are significantly common, but that their relationship is not clear. A metaanalytic study explored different hypotheses for cooccurrence of use of drug of abuse and bipolar disorder. First hypothesis is drug abuse has been identified as a part of bipolar disorder. Second hypothesis postulates that patients use drugs in order to treat symptoms has been suspected. Studies have also shown that the drugs can also cause depression, alcohol use, and bipolar disorder. In all the researches about co-occurrence of bipolar and substance use disorders, all of these results were explicitly established and all play a significant role for drug abuse in bipolar patients.

There has also been an emerging literature focusing on associations of cannabis use in Bipolar patients which shows that most of cannabis users were male having a higher risk of abuse of alcohol and other drugs, have high overall seriousness of the disease, and poorly adhere to medication than non-users, ${ }^{8}$. Particularly alarming is the thing that use of cannabis in bipolar patients increases risk for the onset ${ }^{9}$ of new and longer manic episodes and psychoses incidence ${ }^{8,}{ }^{9}$. There have also been studies that shows that bipolar disorder occurs at an earlier age in people who used cannabis excessively(i.e., > 10 times within one month) as compared to people who used less frequently(i.e., < 10 times within one month) ${ }^{10}$. From previous studies, it was evident that in patients with bipolar disorder cannabis was the most popular substance used ${ }^{11}$. Systematic studies have shown that substance abuse in general and use of cannabinoids specifically can lead to bad treatment response ${ }^{12}$, longer episode or increased intensity of mania, and negative outcomes. ${ }^{13}$. In addition to this, McElroy, et al also described that bipolar patients often have co morbid anxiety disorder and/or substance use disorder. ${ }^{14}$.

With regard to clinical and socio-demographic factors associated with bipolar disorder, there is shortage of studies however it was found that having a bipolar disorder itself is a risk factor for poor social adjustment and marital disruption. It was also associated with significant increase in, health service utilization, use of welfare and disability benefits and suicidality ${ }^{15}$, 16.

In another study, Leboyer ${ }^{17}$, proposed a theoretical model i.e., Age At Onset (AAO) with three sub-groups (17, 27 and 46 years), and found the significance for early and late onset as corresponding to early or middle age onset in bipolar patients.

Similarly, there is an interesting connection between bipolar disorder and socio-economic condition, as early studies indicate an overall correlation between bipolar disorder and the higher social class, but there has been no connection between these two in recent epidemiological studies rather a lower family income in another study ${ }^{18}$. Bipolar affective Disorder is $9^{\text {th }}$ among the causes of global dysfunction in people aged 15years and 44years, according to the World Health Organization (WHO) ${ }^{19}$. Therefore identifying the sociodemographic correlates of drug use in patients with bipolar affective disorder is necessary and by doing this and to do something about them may change the outlook of disease.

\section{METHODS:}

Data was collected from368 patients in a private clinical setting. Patients of both genders and of age 20-45 years, with bipolar disorder were included in this study. Patients with any other co morbid psychiatric disorder and physical illness were excluded from the current study.

A demographic information questionnaire was designed by the researcher to collect study related-data from research participants. The questionnaire was comprised of information regarding age, gender, education, marital status, residence (rural or urban), occupation, monthly income, family system, duration of illness, reasons of starting drugs, current episode of illness (mania, hypomania or depressive), number of drug use, name of drug in use, cost of substance use, family history of drug use, compliance to treatment and number of hospitalizations of patients.

The data was collected through non-probability consecutive Sampling technique, and cross-sectional research design was used. The patients were told about the research and after taking consent they were enrolled in study. Substance (drug) use disorder was diagnosed in accordance with the DSM-5 criteria for substance use disorder.

The data was analyzed using SPSS version 25.0. Quantitative data such as age, monthly income of the patients, duration of illness, number of substance used, cost of drugs and how many times he was hospitalized were shown as mean and standard deviation. Qualitative data such as gender, educational level, marital status, 
place of residence, occupation, family system, reasons of starting drugs, current episode, name of drugs, family history of substance use, compliance to treatment and drug use were presented as frequency and percentages. Data was stratified for all demographic variables. Poststratification chi square test was applied to see effect of the demographic factors on drug use in Bipolar disorder. P-value of $\leq 0.05$ was taken as statistically significant.

\section{RESULTS:}

368 patients with bipolar affective disorder were enrolled in a private clinical setting. The results showed that the average age of the patients was 31.03 years with standard deviation of 5.837, mean monthly income was 229597.82 Pakistani rupees with a standard deviation of 164626.77. The mean duration of illness was 6.54 years with a standard deviation of 5.157. The mean number of drugs used was 2 with a standard deviation of 0.875 . The mean cost of drug was 29945.7 Pakistani rupees with a standard deviation of 19068.8. The mean number of hospitalization was 2.47 with a standard deviation of 1.694.

These quantitative variables and their association with drug use is mentioned in table 1.

Out of 368 bipolar patients, drug abuse was found in 147 patients that is in $39.9 \%$. The details of the qualitative variables is presented in terms of frequency and percentage in table 2 and 3.

Table 1: Showing mean and standard deviation of quantitative variables

\begin{tabular}{ccc}
\hline QUANTITATIVE & MEAN \pm SD & P- \\
VARIABLES & $\mathrm{N}=368$ & VALUE \\
\hline Age (in years) & $31.03 \pm 5.837$ & 0.174 \\
Monthly Income & $229597.82 \pm 164626.77 * *$ & 1.00 \\
Duration Of Illness & $6.54 \pm 5.157$ & 1.00 \\
$\quad$ (in years) & & \\
$\begin{array}{c}\text { Number Of Drugs } \\
\quad \text { Used }\end{array}$ & $2.0 \pm 0.875$ & 0.991 \\
$\begin{array}{c}\text { Cost Of Drug (in } \\
\quad \text { PKR) }\end{array}$ & $29945.7 \pm 19068.8$ & 0.990 \\
$\quad \begin{array}{l}\text { Number Of } \\
\text { Hospitalizations }\end{array}$ & $2.47 \pm 1.694$ & 0.961 \\
\hline
\end{tabular}

$\mathrm{SD}=$ Standard Deviation, *P-value $\leq 0.05$ is

cons22idered as significant, **in Pakistani rupees

Data was stratified for all variables (both quantitative and qualitative). Post stratification chi square test was applied and it showed that none of the quantitative variables (such as age, monthly income, duration of illness, number of drugs used, cost of drug and number of hospitalization) were associated significantly with drug abuse in patients with Bipolar disorder, as indicated by a $\mathrm{p}$ value of $>0.05$ which was insignificant. Whereas, among qualitative variables, significant association was found between drug use and the occupation of the patients, factors leading to initiation of drug use, family history of drug use, current episode and the type of drugs used, as indicated by a Pvalue of $\leq 0.05$ (table 2 and 3 ).

Table 2: Frequency and percentage of qualitative variables

\begin{tabular}{|c|c|c|}
\hline Variables & $\begin{array}{c}\text { Frequency }(\%) \\
\quad \mathrm{N}=368\end{array}$ & P-value \\
\hline \multicolumn{3}{|l|}{ Gender } \\
\hline Male & $217(59 \%)$ & 0.616 \\
\hline Female & $151(41 \%)$ & \\
\hline \multicolumn{3}{|l|}{ Educational Status } \\
\hline Illiterate & $28(7.6 \%)$ & \\
\hline Middle & $49(13.3 \%)$ & \\
\hline Matric & $70(19.1 \%)$ & 0.985 \\
\hline Graduation & $105(28.5 \%)$ & \\
\hline Postgraduation/other & $116(31.5 \%)$ & \\
\hline \multicolumn{3}{|l|}{ Marital Status } \\
\hline Single & $130(35.3 \%)$ & \\
\hline Married & $177(48.1 \%)$ & 0.573 \\
\hline Divorced & $50(13.8 \%)$ & \\
\hline Widowed & $11(3 \%)$ & \\
\hline \multicolumn{3}{|l|}{ Residence } \\
\hline Urban & $280(76.1 \%)$ & 0.970 \\
\hline Rural & $88(23.9 \%)$ & \\
\hline \multicolumn{3}{|l|}{ Occupation } \\
\hline Banker & $28(7.6 \%)$ & \\
\hline Doctor & $32(8.7 \%)$ & \\
\hline Engineer & $38(10.3 \%)$ & \\
\hline Landlord & $51(13.9 \%)$ & \\
\hline Businessman & $59(16.1 \%)$ & $0.006^{*}$ \\
\hline Student & $54(14.7 \%)$ & \\
\hline Housewife & $31(8.4 \%)$ & \\
\hline Teacher & $54(14.6 \%)$ & \\
\hline $\begin{array}{l}\text { Government } \\
\text { employee }\end{array}$ & $11(3.1 \%)$ & \\
\hline Other & $10(2 \%)$ & \\
\hline
\end{tabular}

According to the occupation of the patients, drug abuse was significantly high in Business man, students, teachers, landlords and engineers with a percentage of $16 \%, 14.7 \%, 14.6 \%, 13.9 \%$ and $10.3 \%$ respectively. The most common reason of drug abuse was illness $12 \%$, for recreational purposes $8.2 \%$, under peer pressure $9 \%$ and stress $7.6 \%$. The most common type of drug abused was alcohol $9.2 \%$, poly substance use 
$8.2 \%$, cannabis and benzodiazepines $5.4 \%$ each. Majority of the patients who abused drugs were currently in maniac phase i.e. $18.8 \%$ and in depressive phase i.e. $10.9 \%$.

Table 3: frequency and percentage of qualitative variables

\begin{tabular}{|c|c|c|}
\hline Variables & $\begin{array}{c}\text { Frequency }(\%) \\
\quad \mathrm{N}=368\end{array}$ & P-value \\
\hline \multicolumn{3}{|l|}{ Family System } \\
\hline Nuclear & $108(29.3 \%)$ & \multirow[t]{2}{*}{0.841} \\
\hline Joint & $260(70.7 \%)$ & \\
\hline $\begin{array}{l}\text { Reasons of starting } \\
\text { drugs }\end{array}$ & $30(8.2 \%)$ & \multirow{6}{*}{$0.000 *$} \\
\hline Recreational purpose & $33(9 \%)$ & \\
\hline Peer pressure & $28(7.6 \%)$ & \\
\hline Stress & $12(3.3 \%)$ & \\
\hline Lack of parental & $44(12 \%)$ & \\
\hline bonding & $221(60.1 \%)$ & \\
\hline \multicolumn{3}{|l|}{ Illness } \\
\hline \multicolumn{3}{|l|}{ No drug abuse } \\
\hline \multicolumn{3}{|l|}{ Current Episode } \\
\hline Mania & $172(46.7 \%)$ & \multirow{4}{*}{$0.000 *$} \\
\hline Hypomania & $60(16.3 \%)$ & \\
\hline Depression & $125(34 \%)$ & \\
\hline Mixed & $11(4 \%)$ & \\
\hline \multicolumn{3}{|l|}{$\begin{array}{l}\text { Family History of } \\
\text { Drug Use }\end{array}$} \\
\hline Yes & $178(48.4 \%)$ & \multirow[t]{2}{*}{$0.001 *$} \\
\hline No & $190(51.6 \%)$ & \\
\hline \multicolumn{3}{|l|}{ Type of Drug } \\
\hline Heroin & $19(5.2 \%)$ & \multirow{7}{*}{$0.000 *$} \\
\hline Cannabis & $24(6.5 \%)$ & \\
\hline Marijuana & $20(5.4 \%)$ & \\
\hline Alcohol & $34(9.2 \%)$ & \\
\hline Benzodiazepine & $20(5.4 \%)$ & \\
\hline Poly substance & $30(8.2 \%)$ & \\
\hline No drug use & $221(60.1 \%)$ & \\
\hline \multicolumn{3}{|l|}{$\begin{array}{l}\text { Compliance to } \\
\text { treatment }\end{array}$} \\
\hline Yes & $232(63 \%)$ & 0.211 \\
\hline No & $136(37 \%)$ & \\
\hline
\end{tabular}

$* \mathrm{P}$ value $\leq 0.05$ was significant

\section{DISCUSSION:}

The current study evaluated patient's own reasons which led them to abuse drugs in a sample of patients with bipolar affective disorder. It revealed that about $39.9 \%$ patients with bipolar affective disorder abuse drugs too. This high frequency of drug use was found to be associated significantly with occupation of the patients, type of drug use, reason for starting drugs and family history of drug use. Majority of patients who presented were mainly in maniac phase.

A systematic review conducted by Richardson $\mathrm{T}$ in 2011evaluated the correlates of substance use as reported in numerous studies ${ }^{21}$. These correlates were socio-demographic profile, detailed psychiatric history that included clinical, personal, developmental and family history. The results of the review showed that young age at time of presentation and young age at the time of onset of symptoms, male gender, being married, having bipolar affective disorder type 1, presence of co morbid anxiety and past history of suicide were all predictors of co morbid substance use disorder. Other variables that were evaluated but were not of significant association were educational years, number of hospitalizations and ethnic minority ${ }^{21}$. The results of this review are not similar to current study results. The current study did not find any significant association between age, number of hospitalizations, gender and marital status. However, the current study showed similarly that the educational profile had no impact on substance use in patients with bipolar affective disorder.

In another study, Lagerberg TV in 2010, investigated lifetime rates of illicit substance use in Bipolar disorder relative to the normal population and if there are differences in clinical and functional features between Bipolar patients with and without excessive substance use. According to this study, substance abuse was found in $45 \%$ of the total patients with bipolar affective disorder. The prevalence rates are in close range with that of the current study i.e. $39.9 \%$. The results by Lagerberg TV showed that substance use was associated with a poor level of education, was related to occupational status, scores of Global Assessment of Functioning and compliance with medication. In our study, the results too showed that occupation was related to substance use in bipolar patients, with highest percentage of substance use among businessman, students and teachers. There was no association between level of education and compliance to treatment in current study.

There is inconsistent evidence regarding the differences between bipolar patients with substance use and those without it based on the demographic, clinical and functional characteristics. However, several researches have shown that the presence of co morbid substance use is associated with more severe illness. Thus it is necessary to rule out the co-morbid disorders i.e., substance use disorders in patients with bi-polar disorders to enhance their functionality, and to reduce the occurrence of any other anomaly. It is also necessary to differentially diagnose the patients with bipolar disorder to rule out their tendency of being 
involved in risky behaviors i.e., excessive use of drugs. Such investigations not only help in identifying the disorder accurately but also aid in formulating an effective treatment plan for the patients. This may enable the identification of high risk individuals so that interventions to prevent the development of substance use disorder can be employed.

\section{LIMITATIONS:}

The sample was assessed only once. The sample size only included patients coming to a private setup and therefore those going to the government setups were not included, so the results cannot be generalized effectively. The study did not attempt to identify the impact of treatment.

\section{ETHICAL APPROVAL}

The study was approved by the Ethical Review Committee of Pakistan Psychiatric Research Centre dated January 7, 2020

\section{REFERENCES:}

1. Almeida-Filho N, Mari JD, Coutinho E, Franca JF, Fernandes J, Andreoli SB, et al. Brazilian multi centric study of psychiatric morbidity: methodological features and prevalence estimates. The British Journal of Psychiatry. 1997; 171(6):524529.

2. Weinstock LM, Gaudiano BA, Wenze SJ, EpsteinLubow G, Miller IW. Demographic and clinical characteristics associated with co morbid cannabis use disorders (CUDs) in hospitalized patients with bipolar I disorder. Comprehensive psychiatry. 2016 Feb 1; 65:57-62.

3. Jonas BS, Brody D, Roper M, Narrow WE. Prevalence of mood disorders in a national sample of young American adults. Social Psychiatry and Psychiatric Epidemiology 2003;38:618-624.

4. Moreno DH, Andrade LH. The lifetime prevalence, health services utilization and risk of suicide of bipolar spectrum subjects, including sub threshold categories in the São Paulo ECA study. J Affect Disord. 2005; 87:231-241.

5. American Psychiatric Association. Diagnostic and statistical manual of mental disorders (DSM-5). American Psychiatric Pub; 2013.

6. De Medeiros Alves V, Pereira AC, Silva VL, de Andrade TG, Nardi AE. Associação entre polimorfismos genéticos e transtorno bipolar. Archives of Clinical Psychiatry. 2012; 39(1):34-39.

7. Strakowski SM, DelBello MP. The co-occurrence of bipolar and substance use disorders. Clinical psychology review. 2000; 20(2):191-206.
8. Van Rossum I, Boomsma M, Tenback D, Reed C, van Os J. Does cannabis use affect treatment outcome in bipolar disorder? A longitudinal analysis. The Journal of nervous and mental disease. 2009; 197(1):35-40.

9. Kvitland LR, Melle I, Aminoff SR, Lagerberg TV, Andreassen OA, Ringen PA. Cannabis use in firsttreatment bipolar I disorder: relations to clinical characteristics. Early intervention in psychiatry. 2016; 10(1):36-44.

10. Lagerberg TV, Kvitland LR, Aminoff SR, Aas M, Ringen PA, Andreassen OA, et al. Indications of a dose-response relationship between cannabis use and age at onset in bipolar disorder. Psychiatry research. 2014;215(1):101-104.

11. Strakowski SM, DelBello MP, Fleck DE, Adler CM, Anthenelli RM, Keck PE, et al. Effects of cooccurring alcohol abuse on the course of bipolar disorder following a first hospitalization for mania. Archives of general psychiatry. 2005;62(8):851-858.

12. Calabrese JR, Shelton MD, Bowden CL, Rapport DJ, Suppes T, Shirley ER, et al. Bipolar rapid cycling: focus on depression as its hallmark. The Journal of clinical psychiatry. 2001;62:34-41.

13. Baethge C, Baldessarini RJ, Khalsa HK. Substance Abuse in First-episode Bipolar I Disorder: Indications for Early Intervention. Year Book of Psychiatry \& Applied Mental Health. 2007;2007:198-199.

14. McElroy SL, Altshuler LL, Suppes T, Keck Jr PE, Frye MA, Denicoff KD, et al. Axis I psychiatric comorbidity and its relationship to historical illness variables in 288 patients with bipolar disorder. American Journal of Psychiatry. 2001; 158(3):420426.

15. Judd LL, Akiskal HS. The prevalence and disability of bipolar spectrum disorders in the US population: re-analysis of the ECA database taking into account subthreshold cases. Journal of affective disorders. 2003;73(1-2):123-131.

16. Tucci AM, Kerr-Corrêa F, Dalben I. Ajuste social em pacientes com transtorno afetivo bipolar, unipolar, distimia e depressão dupla. Revista Brasileira de Psiquiatria. 2001;23(2):79-87.

17. Leboyer M, Henry C, Paillere-Martinot ML, Bellivier F. Age at onset in bipolar affective disorders: a review. Bipolar disorders. 2005;7(2):111-118.

18. Eid L, Heim K, Doucette S, McCloskey S, Duffy A, Grof P. Bipolar disorder and socioeconomic status: what is the nature of this relationship?. International journal of bipolar disorders. 2013 Dec;1(1):9.

19. Guilbert JJ. The World Health Report 2001-Mental Health: New Understanding, New Hope. 
20. Maremmani AG, Bacciardi S, Gehring ND, Cambioli L, Schütz C, Jang K, et al. Substance use among homeless individuals with schizophrenia and bipolar disorder. The Journal of nervous and mental disease. 2017 Mar 1;205(3):173-177.

21. Richardson T. Correlates of substance use disorder in bipolar disorder: A systematic review and metaanalysis. Mental Health and Substance Use. 2011 Aug 1;4(3):239-255.

22. Lagerberg TV, Andreassen OA, Ringen PA, Berg AO, Larsson S, Agartz I, et al. Excessive substance use in bipolar disorder is associated with impaired functioning rather than clinical characteristics, a descriptive study. BMC psychiatry. 2010 Dec 1;10(1):9.
AUTHORS' CONTRIBUTION:

MH: Idea, initial research.

SQB: Data collection

AR: Data collection, manuscript writing

AB: Data analysis,

NM: Review article

AA: Proof Reading 